\title{
ESTUDO DE FOLGAS DIAMETRAIS EM TROCADORES DE CALOR CASCO E TUBO COM FLUIDODINÂMICA COMPUTACIONAL
}

\author{
G. B. LEONI, T. S. KLEIN e R. A. MEDRONHO \\ Universidade Federal do Rio de Janeiro, Escola de Química \\ E-mail para contato: gabrielbleoni@gmail.com
}

\begin{abstract}
RESUMO - Os trocadores de calor do tipo Casco e Tubo são um dos trocadores mais utilizados no meio industrial. Dessa forma, é importante o estudo dos fenômenos físicos que ocorrem no seu interior, principalmente em seu casco, onde o escoamento tortuoso do fluido pelos tubos e chicanas é de difícil modelagem. O presente trabalho apresenta o projeto e análise, com fluidodinâmica computacional (CFD), de um trocador de calor Casco e Tubo. Nesse trocador, há óleo escoando no casco a fim de ser aquecido, enquanto água de utilidade quente escoa nos tubos. Para o projeto do trocador, utilizou-se o software HTRI 6.0, o qual fornece o perfil de temperatura ao longo dos tubos e do casco. O primeiro foi utilizado na simulação com CFD para especificar a temperatura nos tubos como função da posição ao longo do eixo longitudinal do trocador. Foram consideradas geometrias com e sem as folgas diametrais, as quais são responsáveis pela formação de correntes de fuga, de modo a comprovar sua importância para correta predição do escoamento e troca térmica. Foram testados os modelos de turbulência $k-\varepsilon$ e SST, sendo o último o modelo que forneceu melhores predições. Os resultados obtidos com CFD mostraram boa compatibilidade com os resultados do perfil de temperatura e pressão obtidos com o HTRI. Além disso, as correntes de fuga foram quantificadas e comparadas com as estimadas pelo HTRI, obtendo-se resultados bastante próximos.
\end{abstract}

\section{INTRODUÇÃO}

Um dos equipamentos mais comuns e amplamente utilizados na indústria é o trocador de calor do tipo Casco e Tubo, onde o grande desafio de seu projeto está em estimar o coeficiente de troca térmica no lado do casco. Esse depende de uma série de parâmetros como: o número e posicionamento de internos (chicanas e suportes), posicionamento e tamanho dos bocais, layout dos tubos, dentre outros.

Normalmente, o projeto desses trocadores de calor se dá através de programas comerciais que estimam os coeficientes de troca globais do processo de modo a determinar a área necessária para a realização do serviço. Entretanto, quando tais programas são utilizados, obtêm-se apenas as características gerais do processo, não sendo fornecidas informações mais detalhadas sobre o escoamento interno.

Nesse contexto, a fluidodinâmica computacional (CFD) vem sendo bastante utilizada para previsão do comportamento dos fluidos e melhor compreensão dos fenômenos físicos envolvidos 
no processo, como zonas de recirculação e relaminarização (Ozden e Tari, 2009).

Porém, grande parte desses estudos com CFD não considera a presença de folgas diametrais na geometria. As folgas diametrais são elementos obrigatórios na construção de um trocador de calor do tipo Casco e Tubo, representando o espaçamento entre o tubo e a chicana (diferença entre o diâmetro externo do tubo e o diâmetro da região onde o mesmo é inserido na chicana - folga diametral tubo-chicana) e o espaçamento entre o casco e a chicana (diferença entre o diâmetro externo da chicana e o diâmetro interno do casco - folga diametral casco-chicana). Como há diferença de pressão entre a região a montante e a jusante à chicana, há também o escoamento de fluido através de tais espaçamentos (Bell, 1963), gerando correntes de fuga, as quais são descritas pelo modelo de correntes de Tinker. Segundo esse modelo a corrente A representa o fluxo de massa através das folgas diametrais entre os tubos e as chicanas; $\mathbf{B}$ equivale a corrente principal, transversal aos tubos; $\mathbf{C}$ corrente que escoa em volta dos feixe de tubos e $\mathbf{E}$ fluxo atraves das folgas diametrais entre o casco e as chicanas.

Ozden \& Tari (2009) estudaram o escoamento dentro do casco de um trocador de calor do tipo Casco e Tubo de pequeno porte com chicanas simplesmente segmentadas com CFD. Ainda que não tenham considerado a presença de folgas diametrais, promoveram o estudo das melhores condições para a relação entre entre o número de chicanas, espaçamento e a porcentagem de corte das mesmas. Seguindo uma vertente diferente da utilização de chicanas segmentadas, Zhang et al. (2009) e Wang et al.(2008) promoveram estudos de trocadores de calor do tipo Casco e Tubo com chicanas helicoidais, sem considerar, também, o efeito da presença de folgas diametrais sobre o escoamento. Diferentemente dos estudos mencionados, Mohammadi (2011) promoveu a análise com CFD de um trocador de calor Casco e Tubo com chicanas simplesmente segmentadas, considerando folgas diametrais, variando a orientação das mesmas, de forma a identificar a mais apropriada para o tipo de fluido que escoava no casco, entretanto não promoveu a validação de sua análise com uma geometria equivalente.

Dessa forma, o presente trabalho visa comparar simulações de geometrias com e sem folgas diametrais de forma a obter um melhor compreendimento da importância e dos efeitos das correntes de fuga no escoamento ao longo do casco do trocador, além de testar a performance de dois modelos de turbulência, o $k-\varepsilon$ e o SST, no estudo do escoamento.

\section{METODOLOGIA}

A primeira parte do estudo deu-se por meio do projeto de um trocador de calor Casco e Tubo, utilizando-se o software comercial HTRI, o qual é empregado por diversas empresas, devido à sua confiabilidade e precisão. Nesse software foram inseridos os dados do processo, os quais se baseiam em um óleo escoando dentro do casco de um trocador de calor, sendo aquecido por água de utilidade à alta pressão. $\mathrm{O}$ óleo foi aquecido de $90^{\circ} \mathrm{C}$ à $106,86^{\circ} \mathrm{C}$ com uma vazão mássica de 3,5 kg/s. Já a água, pressurizada, tem vazão mássica 1,41de $\mathrm{kg} / \mathrm{s}$ e entra nos tubos a $170^{\circ} \mathrm{C}$ e sai à $190^{\circ} \mathrm{C}$. A Tabela apresenta as dimensões e parâmetros importantes obtidos com o HTRI e utilizados para gerar a geometria utilizada na simulação com CFD. Geometria essa, ilustrada na Figura . 
Tabela 1 - Dimensões e parâmetros referentes à geometria projetada pelo HTRI.

\begin{tabular}{cc}
\hline Parâmetro & Valor \\
\hline Diâmetro do casco & $0,205 \mathrm{~m}$ \\
Comprimento efetivo & $1,061 \mathrm{~m}$ \\
Espaçamento entre as chicanas & $0,160 \mathrm{~m}$ \\
Corte das chicanas & $35 \%$ \\
Número de chicanas & 4 \\
Folga diametral tubo-chicana & $8,000 \times 10^{-4} \mathrm{~m}$ \\
Folga diametral casco-chicana & $3,180 \times 10^{-3} \mathrm{~m}$ \\
Número de tubos & 43 \\
\hline
\end{tabular}
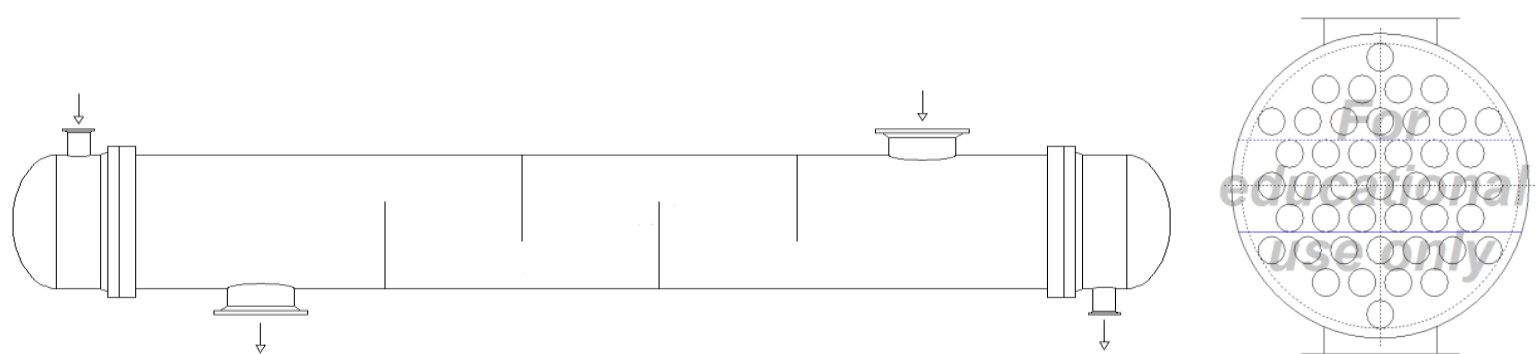

Figura 1 - Geometria do trocador de calor Casco e Tubo e layout dos tubos projetados pelo HTRI.

A fim de se comparar a forma como as folgas diametrais iriam impactar no escoamento, desenharam-se duas geometrias, uma com folgas diametrais - segundo as especificações contidas na Tabela - e outra sem, ou seja, considerando que os tubos fossem soldados nas chicanas e estas, nos casco. Cabe ressaltar que o escoamento dentro dos tubos não foi simulado, mas seu perfil de temperatura foi especificado para cálculo do fluxo de calor, e que as chicanas consistem em paredes sólidas.

O teste de malha foi feito a partir da geometria sem folgas diametrais. Foram geradas malhas com 3.503.635, 5.690.305 e 8.762.473 elementos, nomeadas de 3.5MI, 5.6MI e 8.7MI, respectivamente. Todas as malhas foram simuladas com os modelos SST e $k$ - $\varepsilon$, de forma a identificar o modelo mais adequado para resolução do problema, nas malhas geradas. Como parâmetro de comparação para identificação da malha e modelo mais adequado utilizou-se o perfil de temperatura do casco ao longo do eixo longitudinal do mesmo.

O resultado das simulações com o modelo SST apresentou perfis de temperatura muito parecidos para todas as malhas, porém houve alguns pontos destoantes para a malha 3.5MI. Assim, consideraram-se os resultados da malha 5.6MI como independentes. Para simulações com modelo $k-\varepsilon$, os resultados das três malhas geradas também foram muito próximos, porém pode-se notar na Figura 2 que os perfis obtidos com o modelo SST estão mais próximos aos fornecidos pelo HTRI que aqueles obtidos com o modelo $k$ - $\varepsilon$. Vale ressaltar que o HTRI calcula a temperatura média, tanto no casco quanto nos tubos, em posições específicas localizadas na posição média entre as chicanas, induzindo a um perfil linear. Porém, com CFD, é possível analisar os perfis em várias posições ao longo do trocador, mostrando que logo após as chicanas há picos de temperatura, causado pelas zonas de recirculação, como pode ser visto na Figura 3. 

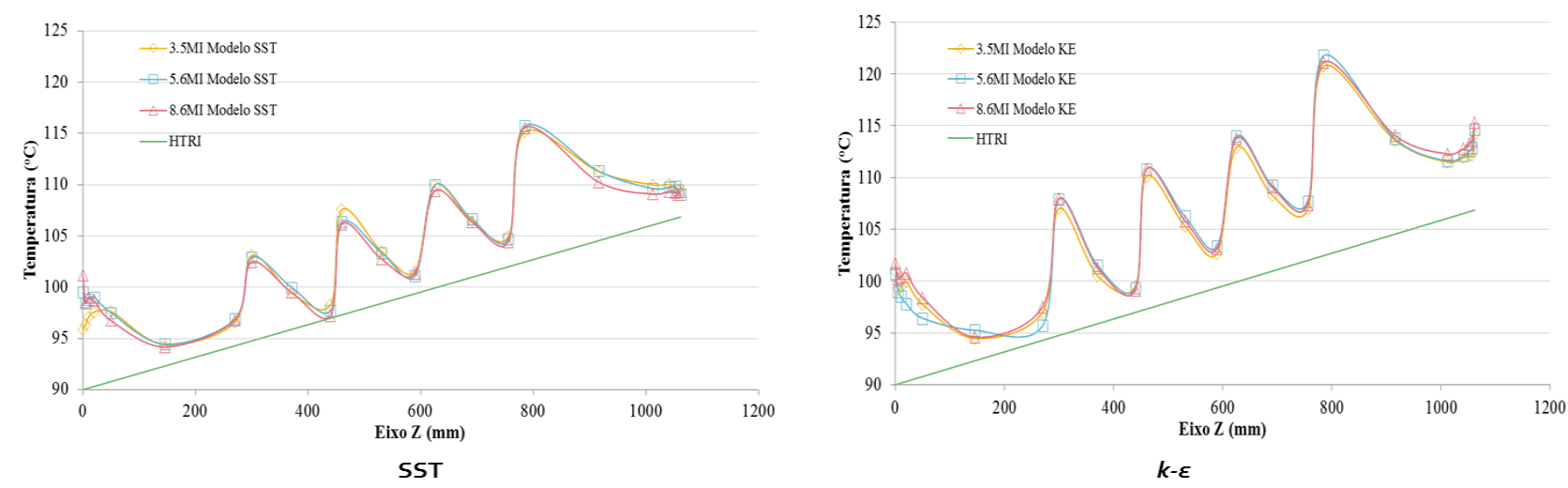

Figura 2 - Perfis de temperatura para o modelo de turbulência SST (esquerda) e $k-\varepsilon$ (direita) sendo comparados com o perfil de temperatura obtido pela HTRI (reta verde).

Considerou-se, então, o modelo SST como o mais apropriado para descrição do escoamento dentro do casco. Tal fato já era esperado, uma vez que o modelo SST resolve a região próxima à parede, afetada pela viscosidade, na qual ocorrem os maiores gradientes de velocidade, responsáveis pela geração de turbulência, em oposição ao modelo $k$ - $\varepsilon$ que utiliza funções de parede.

Para a geometria contendo folgas diametrais foi construída apenas uma malha com 8.640.672 (ESP 8.6MI) elementos. Nessa, foram mantidas as principais características da malha referente à geometria sem folgas, além de atender o número mínimo de elementos considerados necessários para obtenção de resultados independentes da malha para a simulação do trocador numa geometria sem folgas diametrais (malha 5.6MI).

\section{RESULTADOS E DISCUSSÃO}

\subsection{Geometria sem folgas diametrais}

Os resultados para a geometria sem folgas diametrais encontram-se na Figura 3.

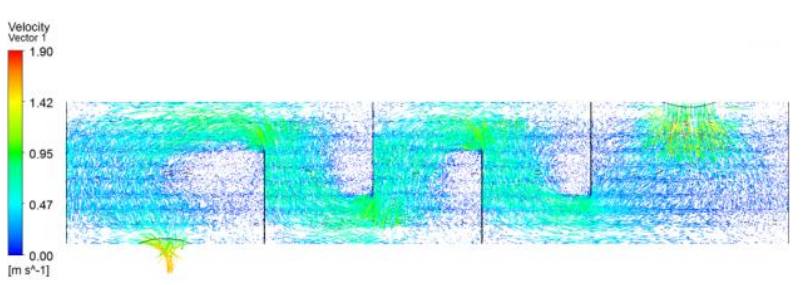

(a)

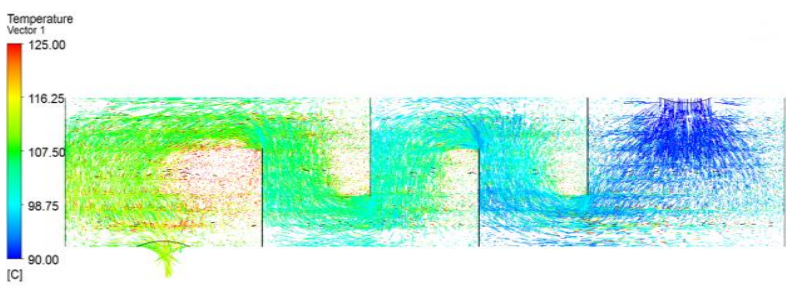

(b)

Figura 3 - Vetores velocidade, em escala, coloridos (a) pelo módulo dos vetores velocidade e (b) pela temperatura para o caso sem folga diametral.

Como pode ser visto através da imagem da Figura 3(a), a velocidade dentro do trocador tem um valor máximo de $1,90 \mathrm{~m} / \mathrm{s}$, porém apresenta regiões de estagnação do fluido, também 


\section{9 a 22 de outubro de 2014 \\ Florianópolis/SC}

chamadas de zonas mortas. Tais regiões podem ser identificadas principalmente próximas à entrada, saída e após as chicanas, onde os vetores velocidade assumem valores que tendem à zero. É possível perceber ainda o aumento de velocidade nas regiões de corte da chicana, fato que, como será visto mais a frente, ocasionará queda brusca local no valor da pressão. Na imagem da Figura 3(b), visualiza-se o aumento local de temperatura nas zonas mortas localizadas atrás das chicanas. A temperatura máxima obtida no trocador foi de $125^{\circ} \mathrm{C}$, valor bem acima da temperatura final proposta para o serviço $\left(106,86^{\circ} \mathrm{C}\right)$.

\subsection{Geometria com folgas diametrais}

Os resultados para a geometria com folgas diametrais encontram-se na Figura .

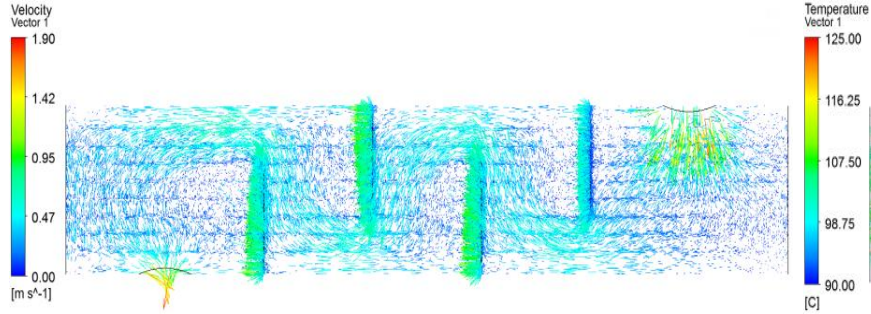

(a)

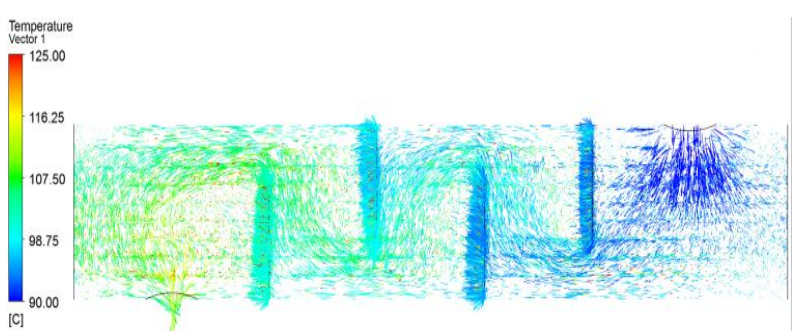

(b)

Figura 4 - Vetores velocidade, em escala, coloridos (a) pelo módulo dos vetores velocidade e (b) pela temperatura para o caso com folga diametral.

Diferentemente da geometria sem folgas diametrais, é possível visualizar na Figura os vetores correspondentes ao fluxo de massa das correntes de fuga. Ainda é possível perceber a presença de zonas de recirculação atrás das chicanas, porém, essas são menores e os vetores velocidades são mais intensos.

A Figura mostra aumentos de temperatura nas zonas de recirculação, porém não tão altos como os presenciados na geometria sem folgas diametrais (Figura 3(b)), principalmente pela dissipação de tais zonas pelas correntes de fuga, que atuam no sentido de homogeneizar mais a temperatura.

Conclui-se que as correntes de fuga promovem a dissipação das zonas de recirculação localizadas atrás das chicanas com consequente diminuição nos picos de temperatura.

\subsection{Comparação dos Resultados com o HTRI}

Uma vez que o programa HTRI é amplamente utilizado para projeto de trocadores de calor e determinação de parâmetros de troca térmica, realizou-se a comparação dos resultados fornecidos por esse programa com os obtidos nas simulações com CFD para as geometrias com e sem folgas diametrais. A Figura mostra a comparação dos perfis de temperatura ao longo do trocador. 


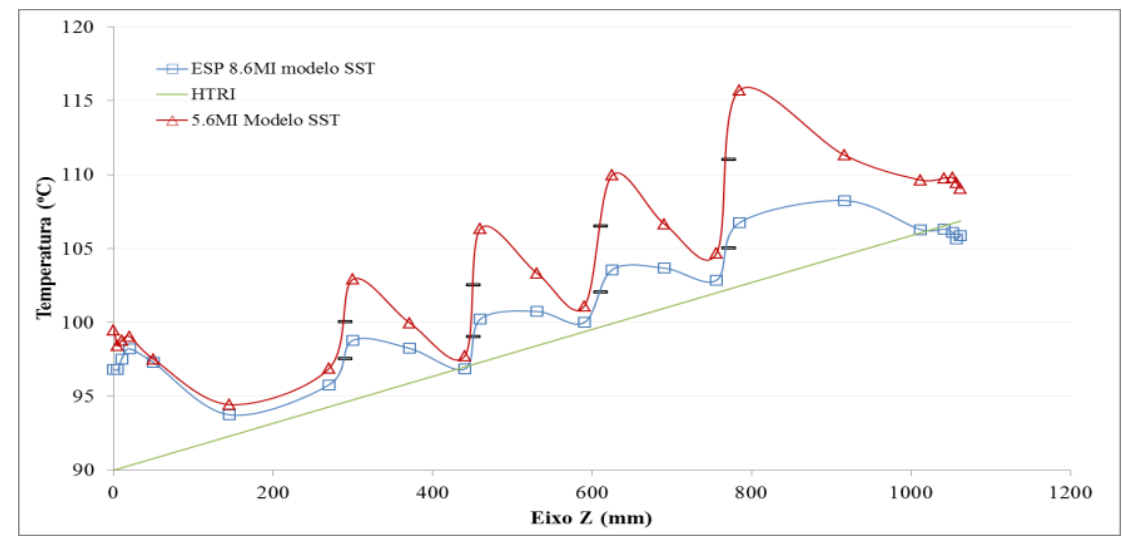

Figura 5 - Comparação dos perfis de temperatura ao longo do eixo longitudinal do trocador (eixo Z) obtidos com o HTRI e com CFD para os casos sem folgas (5.6MI) e com folgas (ESP 8.6MI), sendo o traço horizontal de cor preta a posição geométrica das chicanas.

Conforme já indicado pelas Figuras 3(b) e 4(b), é possível perceber, a partir do perfil de temperatura, que a geometria sem folgas diametrais apresenta picos de temperatura, logo após as chicanas, mais pronunciados que para a geometria com folgas. Assim, pode-se inferir que esse é um dos efeitos marcantes da presença de correntes de fuga em um trocador: dissipar as regiões de estagnação, minimizando superaquecimento local. Em regiões onde não há a presença de correntes de fuga, como por exemplo a região onde $\mathrm{Z}=0$, a temperatura no casco atinge valores relativamente altos, para as duas geometrias.

Através da Figura , a qual apresenta os perfis de pressão ao longo do trocador de calor, é possível visualizar quedas bruscas de pressão durante a passagem do fluido pelo corte da chicana, porém, assim como para a temperatura, as variações de pressão são mais brandas para geometria com folgas diametrais. É possível inferir que as folgas diametrais sirvam como válvulas de escape para o fluido, que, na malha sem as folgas, podia escoar apenas pelo corte da chicana. A comparação da queda de pressão e temperatura de saída, previstas para o trocador pelo HTRI e pelas simulações com CFD, pode ser vista na Tabela .

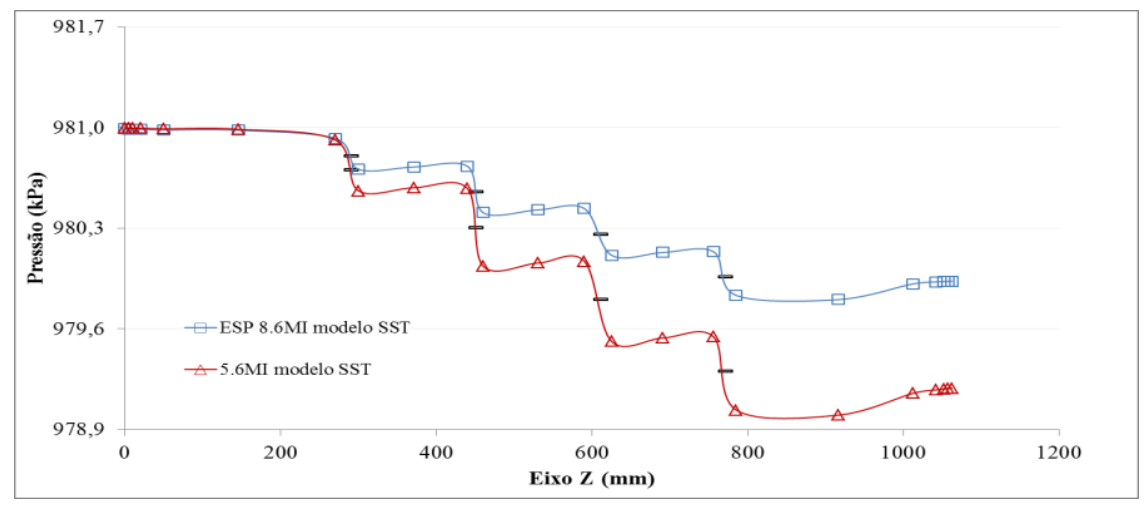

Figura 6 - Comparação dos perfis de pressão ao longo do eixo longitudinal do trocador (eixo Z) para a malha 5.6MI e ESP 8.6MI, sendo o traço horizontal de cor preta a posição geométrica das chicanas. 
Tabela 2 - Comparação de queda de pressão ao longo do trocador medida a partir da região do bocal de entrada e região do bocal de saída.

\begin{tabular}{ccc}
\hline Simulação & $\Delta \mathrm{P}(\mathrm{kPa})$ & $\mathrm{T}_{\text {saída }}\left({ }^{\circ} \mathrm{C}\right)$ \\
\hline HTRI & 1,26 & 106,86 \\
CFD sem folga diametral (5.6MI) & 1,99 & 110,60 \\
CFD com folga diametral (ESP 8.6MI) & 1,18 & 106,70 \\
\hline
\end{tabular}

Pode-se verificar que a simulação com CFD do caso com folgas diametrais retornou resultados muito próximos àqueles do HRTI.

A comparação da previsão das correntes de fuga, segundo o modelo de correntes de Tinker, pode ser visualizada na Tabela 3.

Tabela 3 - Comparação das correntes segundo o modelo de correntes de Tinker.

\begin{tabular}{ccccc}
\hline \multirow{2}{*}{ Corrente } & \multicolumn{2}{c}{ CFD - com folga diametral } & \multicolumn{2}{c}{ HTRI } \\
& $\mathrm{kg} / \mathrm{s}$ & $\%$ & $\mathrm{~kg} / \mathrm{s}$ & $\%$ \\
\hline A & 0,28 & 7,90 & 0,20 & 5,70 \\
E & 0,39 & 11,09 & 0,52 & 15,00 \\
B & 2,39 & 68,49 & 2,37 & 67,60 \\
C & 0,44 & 12,52 & 0,41 & 11,60 \\
TOTAL & 3,50 & 100,00 & 3,50 & 100,00 \\
\hline
\end{tabular}

A partir da tabela acima é possível perceber uma maior similaridade entre os resultados da simulação com CFD e os resultados do HTRI nas correntes $A, B$ e $C$. A corrente E apresentou um maior distanciamento dos resultados entre a simulação com CFD $(11,09 \%)$ e o HTRI $(15,00 \%)$. Pode-se investigar se um maior refinamento na região da parede do casco viria a melhorar esse resultado.

\section{CONCLUSÕES}

O presente trabalho comparou simulações com CFD de trocadores de calor do tipo casco e tubo com e sem folgas diametrais. A partir dos resultados apresentados, pode-se concluir que, entre os modelos de turbulência $k$ - $\varepsilon$ e SST, o último é mais indicado para simulações de trocador casco e tubo, devido à importância de regiões de parede (tubos, chicanas e casco) que influenciam o escoamento principal.

A validação da simulação com CFD foi feita através da comparação dos resultados obtidos para a geometria com folga diametral àqueles fornecidos pelo HTRI, programa utilizado para projeto de trocadores. Para essa configuração, obtiveram-se valores de temperatura de saída e queda de pressão muito próximos aos previstos pelo HTRI, além de uma concordância razoável das percentagens das correntes de fuga. 
Identificou-se também a importância de se simular com CFD as folgas diametrais, as quais permitem a formação das correntes de fuga, pois estas atenuam as zonas de recirculação, minimizando as variações e picos de temperatura e pressão ao longo do eixo longitudinal do trocador. Esse resultado é bastante importante, pois indica que a redução das correntes de fuga (normalmente desejado no projeto de trocadores para aumentar a troca térmica) pode gerar picos de temperatura locais maiores, que podem ser críticos dependendo do serviço.

\section{AGRADECIMENTOS}

Os autores agradecem ao CNPq pela bolsa de pós-doutorado.

\section{REFERÊNCIAS}

BELL, K. J. Final Report of the Cooperative Research Program on Shell and Tube Heat Exchangers. p 1-33, 1963. Newark, Delaware.

MENTER, F. R. Two-Equation Eddy-Viscosity Turbulence Models for Engineering Applications. AIAA Journal, v. 32, p. 1598-1605, 1994.

MOHAMMADI, K. Investigation of the Effects of Baffle Orientation, Baffle Cut and Fluid Viscosity on Shell Side Pressure Drop and Heat Transfer Coefficient in an E-Type Shell and Tube Heat Exchanger. Stuttgart, 2011.

Ozden, E.; Tari, I. Shell Side CFD Analysis of Small Shell-and-Tube Heat Exchanger. Energy Conversion and Management, v. 51, p. 1004-1014, 2009.

SUKHATME, S. E. Heat Transfer Equipment Design. Washington: Hemisphere Publ. Co., 1988.

WANG, Q.; CHEN, Q.; CHEN, G.; ZENG, M. Numerical Investigation on Combined Multiple Shell-Pass Shell-and-Tube Heat Exchanger with Continuous Helical Baffles. Int. J. of Heat and Mass Transfer, v. 52, p. 1214-1222, 2008.

ZHANG, J.; HE, Y.; TAO, W. 3D Numerical Simulation on Shell-and-Tube Heat Exchangerwith Middle-overlapped Helical Baffles and Continuous Baffles - Part I: Numerical Model and Results of the Whole Heat Exchangerwith Middle Overlapped Helical Baffles. Int. J. of Heat and Mass Transfer, v. 52, p. 5371-5380, 2009. 